\title{
Technology Enhanced PBL in HCI Education: A Case Study
}

\author{
Christina Vasiliou, Andri Ioannou, and Panayiotis Zaphiris \\ Cyprus University of Technology \\ Limassol, Cyprus \\ \{c.vasiliou, andri.i.ioannou, panayiotis.zaphiris\}@cut.ac.cy
}

\begin{abstract}
Problem Based Learning (PBL) is an instructional method in which the base for learning is a real-world problem. A typical PBL setting is comprised of students working together on an authentic problem, using simple tools such as whiteboards and stationery. Online tools and multimedia technologies have also been used to support PBL activities. There is however no empirical work on the blended use of both physical and digital tools. This paper presents a case study in which we employed PBL pedagogy for the teaching of a postgraduate course in Human Computer Interaction (HCI). The activities were situated in a multimodal information space, rich in digital and physical elements including personal computers, projectors with downwards projection, tablets, iPods, digital pen readers, stationery and a Facebook group for each team. We administrated questionnaires assessing students' motivational beliefs and overall satisfaction with the learning experience. Our results show that students' overall satisfaction was highly rated, while the information space contributed to students' engagement and collaboration.
\end{abstract}

Keywords: Problem based learning, HCI education, Multi-modal interfaces.

\section{Introduction}

A common barrier in acquiring knowledge presented in class is that students are often disengaged from active collaboration, interaction and reflection. Problem based learning (PBL) is a didactic approach in which the base of learning is the need to solve a real-world problem [1] and providing context-rich situations [2]. A typical PBL setting is comprised by students working together on the problem, using simple stationery. With the advancement of the technology new ideas were brought forefront. Online tools such as forums and blogs, as well as multimedia enriched settings, including games, have been used to support PBL. There is however no empirical support on using both physical and digital tools together in a PBL setting. Specifically, this study attempts to achieve a two-fold purpose by integrating PBL in a technology enhanced environment: first, to explore its possibilities and constraints for teaching HCI; and second, to explore how this space promotes learners' collaboration and engagement. 


\section{Literature Review}

As this research project focuses on the use of PBL pedagogy and the use of technology, this section will present a review of traditional PBL as well as technology enhanced PBL case studies.

\subsection{Problem Based Learning}

PBL is an instructional method in which, problem is the trigger that initiates learning; while students work in small collaborative groups to solve it [3]. Therefore, students take the responsibility of their own learning objectives and new information is expected to come from their investigation towards the solution of the problem. A traditional PBL setting is comprised by students working together on the problem using simple physical elements such as markers, whiteboard and post-it notes.

\subsection{Use of Technology in PBL}

Online Tools and PBL Environments. Initial forms of technology included Internet purely for online research or online tools and environments to facilitate PBL. Several forms of synchronous and asynchronous communication tools and online environments have been identified among studies, such as WebCT [4], Blackboard [5], Blogs and Wikis [6]. Results showed that students preferred to communicate real time due to the immediate type of communication simulating physical interaction [6].

With these results, a blended model of PBL was implemented integrating face-to face and online interactions [7]. Through the literature analysis, we identified two approaches, based on the leading party. Studies where the leading role is retained by the online environment embraced the need for physical meetings, requiring a number of physical meetings either for progress reflection and feedback [8] or for face-to-face PBL sessions [9][10]. In the second approach, face-to-face PBL sessions are followed by the use of online tools for communicating, sharing and reflecting [11][12][13]. Another study [14], enhanced digital elements in class with the use of an interactive whiteboard to support group collaboration. Overall, with blended environments, students felt more willing to get involved in learning and felt satisfied with the flexibility in time for online tools [13].

PBL within Multimedia, Games and Virtual Worlds. The second main pathway in the use of technology in PBL is multimedia. Researchers created multimedia enriched environments successfully increasing students' motivation [15][16]. Due to their popularity [17], games were also embraced by PBL community, with efforts made to understand game elements that can lead to the improvement of educational technologies, enhancing students' engagement [18]. Redesigned courses were highly rated by students, but no significant changes were found in terms of learning.

What appears to be a tendency lately is the use of 3D virtual worlds for the development of virtual spaces where learners could engage in problem solving, waving the confrontment of their decisions' consequences [19]. One of the most widely used 3D 
environments in educational settings is Second Life (SL), mainly due to its abilities of building rich 3-D environments, highly immersive for players with a relatively low cost to participate [20]. In brief, studies showed that 3-D worlds offered a fun and engaging approach towards learning, while the involvement of professionals and the context of future tasks in a realistic setting increased their motivation [21].

Identifying a Gap in Knowledge. Online and multimedia environments have all been extensively used in PBL studies, but little attention has been paid to the blend of digital and physical elements during in-class activities. Results were positive towards engaging students through the blended form of in-class activities [14], raising the following questions: Does the interaction between a variety of physical and digital elements in the PBL environment promote learners' engagement and collaboration? To address this, our study set out to develop a multimodal information space, including both digital and physical elements and to further investigate how this space promotes students' engagement and collaboration.

\section{Methods}

This research aims at developing a blended multimodal information space and evaluating the levels of engagement and collaboration. The following section demonstrates the case study, describing in detail the blend of physical and digital elements, the developed information space and the data collection process.

\subsection{Participants}

The sample was composed of 30 postgraduate students (11 males and 19 females) enrolled in an HCI course. Students' background was multidisciplinary including studies such as computer science and games, graphic arts and multimedia or education and communication. The participants were divided into five groups ( 5 groups of 5 to 7 students), each formed with students from different disciplines.

\subsection{Procedures}

PBL Curriculum and Course Structure. A traditional lecture based Human Computer Interaction (HCI) post-graduate course was reformed to fit PBL. The HCI course was organized in 3 hour weekly sessions, including mini lectures and group activities.

The mini lectures were intended not to directly provide content, but form students stimulus to progress with their own research and acquire knowledge on their own, matching the PBL pedagogy[2]. As Hmelo-Silver indicated "a lecture at the right time may be beneficial", denoting that in the process of solving a problem it might be necessary to provide certain information to the learner to support self-directed learning.

Group activities aimed to enable student engagement and active collaboration within each group were usually two hours long and consisted of three main units: 
(1) Weekly Reflection: A 20 minutes session to summarize and reflect on what has been done since the last laboratory session. (2) Brainstorming: Usually 80 minutes session to discuss about the progress of the project, readjust the problem based on the new facts and discuss ideas. (3) Self Study Assignment: A 20 minutes session to define what are the groups learning objectives and form a to-do list.

Problem. The problem given to students for the design project was derived from CHI2013 student design competition scenario, entitled "Empowering the Crowd: Changing Perspectives Through Collaboration"[22]. Problems are of crucial importance to the success of PBL [1]. The selection of the current problem scenario was based on the need for a challenging, real world problem.

Setting. The blended delivery format of PBL enclosed a combination of traditional face to face and online interactions, rich in digital and physical tools. Its main features include whiteboard, post-it notes, markers and other stationery, typical for traditional PBL and expanding it with a set of digital tools. More specifically, a ceiling-mounted projector for downwards projection, one or more personal computers, one tablet, one iPod, one sense camera and an infrared pen and pen reader (IPPR) per group. The structure of the multimodal information space used in our study is shown in Figure 1.

Small technologies and gadgets, such as iPods, tablets and stationery, were grouped and organized in a box, constructing our "Creativity Box" (CB). A detailed guide was developed and distributed to the students during the first week laboratory with the purpose of learning how to use each element. Students were instructed to use the provided technologies freely, with no limitations on how and when to use each element. Figure 1, demonstrates individual use of digital elements included in the information space. Facebook was used as the medium for synchronous and asynchronous interactions allowing participants to communicate and share material. Due to scope and space limitations of this paper, Facebook data analysis and results will be presented elsewhere.
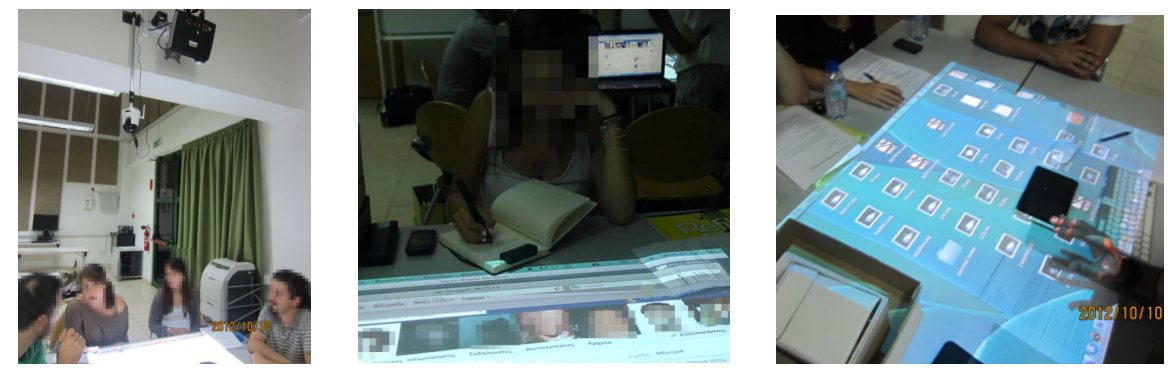

Fig. 1. Left: Structure of the multimodal information space. Center: Taking digital notes. Right: Downward projection as a shared screen.

\subsection{Data Collection}

Questionnaires were constructed, mainly with the aim of gauging students' views of how the information space setup supported their collaborative work. All questionnaires 
were administrated after the full duration of the course and included Likert-type items with a 7-point agreement response scale (from 1: completely disagree to 7: completely agree).

The first questionnaire concerned students' motivational beliefs, to measure three constructs of interest: (1) Motivation, measuring task value and academic self efficacy, (2) Technology Expectations and (3) Technology Self-Efficacy. The second questionnaire was dealing with students' collaboration experience based on five constructs of interest: (1) Communication and Interaction, (2) Reflection, (3) Perceived Learning, (4) Overall Satisfaction, and (5) Frustration.

Open ended questions were given to the participants concerning the way each group functioned throughout laboratory activities, such as "Did you assign roles?", "Did you split the work?" and addressing issues on teamwork and the setting.

\section{$4 \quad$ Results}

Upon the completion of the research study, all the recorded data were analyzed with mixed methods. The current section presents an overview of the results from the post questionnaires and open ended questions.

\subsection{Post Questionnaires}

Due to missing data, results only from 29 students were reported and analysed. First the internal consistency for each subscale was assessed using Cronbach's alpha; all 9 subscales had acceptable internal consistency (Cronbach's alphas > .70). Afterwards, all subscale mean scores were calculated. As demonstrated in Table 1, subscale mean scores were all above the midpoint of the response scale suggesting that participants found their activities useful and important $(\mathrm{M}=6.02, \mathrm{SD}=.75)$ and felt confident with the use of technology $(\mathrm{M}=5.89, \mathrm{SD}=.74)$. As demonstrated in Table 2, mean scores were above the midpoint of the response scale for the first four measures, and way below midpoint for Frustration, suggesting that educational technology and collaborative activities were positively embraced by the students. The participants indicated that overall their collaborative learning experience satisfaction was high $(\mathrm{M}=6.01$, $\mathrm{SD}=.87$ ) and that the activity was successful in promoting the construction of knowledge $(\mathrm{M}=6.25, \mathrm{SD}=.75)$, critical thinking and reflection $(\mathrm{M}=5.79, \mathrm{SD}=.93)$.It is also important to denote that even though frustration levels were clearly below the midpoint of the response scale, the variations in answers among the students was high $(\mathrm{M}=2, \mathrm{SD}=1.22)$.

Table 1. Subscales and Descriptive Statistics for Post Questionnaire on Motivation ( $N=29)$

\begin{tabular}{llll}
\hline Subscale & \# Items & Cronbach's Alpha & Means (SD) \\
\hline 1. a) Task Value & 6 & .890 & $6.02(.75)$ \\
b) Academic Self-Efficacy & 6 & .893 & $5.64(.65)$ \\
2. Technology Expectations & 6 & .963 & $5.57(1.07)$ \\
3. Technology Self-Efficacy & 6 & .926 & $5.89(.74)$ \\
\hline
\end{tabular}


Table 2. Subscales and Descriptive Statistics for Post Questionnaire on Collaboration ( $=29)$

\begin{tabular}{llll}
\hline Subscale & \# Items & Cronbach's Alpha & Means (SD) \\
\hline 1. Communication and Interaction & 6 & .855 & $6.16(.62)$ \\
2. Reflection & 5 & .908 & $5.79(.93)$ \\
3. Perceived Learning & 5 & .776 & $6.25(.75)$ \\
4. Overall Satisfaction & 5 & .927 & $6.01(.87)$ \\
5. Frustration & 4 & .789 & $2.00(1.22)$ \\
\hline
\end{tabular}

\subsection{Open-Ended Questions}

Qualitative feedback was in line with previous findings in that students were positive overall concerning the functioning of their group and the course structure. In terms of course structure and collaborative work, students stated that "It was a wonderful experience!", or "Great and effective way of organizing the lesson". In terms of the information space participants supported the use of technologies in class supporting that "Technologies provided in class helped us". The majority of the participants further reported good collaboration and communication between team members, equality in group work and satisfaction with the final product, suggesting high levels of agreement and collaboration within the group.

On the negative side, a few participants found the use of some technologies was frustrating or not really useful. This finding is in line with questionnaire results that indicated low levels of frustration but with great variations, suggesting that few participants found the developed information space more challenging than others or some certain technologies not as useful as others. This is something we seek to investigate further in future work.

\section{Discussion}

This study set out with the aim to develop a multimodal information space, including both digital and physical elements and to further investigate how this space enhances learners' collaboration and engagement. The results of the questionnaires and open ended questions indicate that the developed information space was positively perceived by students, engaging and motivating them towards learning.

Regarding our first goal to investigate the blended form of the multimodal information space, our findings indicate that the blend was successful but improvement areas have been identified. Similarly to [14], students embraced the blended mode of instruction with increased satisfaction as demonstrated from questionnaires. But, high variations in frustration levels, based on questionnaires and different opinions from qualitative feedback, show us that elements included in the information space, especially digital tools, should be further investigated.

On the question of whether the developed information space enhanced students' collaboration and engagement the study found that to be true. Based on the questionnaire results, participants demonstrated high levels of communication and interaction and found class activities useful and valuable. Furthermore, our results lend support to 
previous studies indicating that engagement and motivation are highly rated in technology enhance PBL environments or curriculums, especially when including multimedia [16]. Students' exhibit enthusiasm and positive attitude towards the course and group activities as identified within the qualitative feedback. All these are indicators of students' engagement and collaboration in the process of learning, answering the second part of our research aim.

Although the research has reached its two-fold target, a number of important limitations need to be considered. This research was conducted on a small size population attending the HCI course; therefore, results cannot be generalized. Another potential limitation of this study is not measuring learning through this multimodal information space to successfully identify it as a learning space.

\section{Conclusion}

This paper presented a case study in which we employed PBL pedagogy for the teaching of a post-graduate course in HCI. Our results show that students' overall satisfaction was highly rated, while the information space contributed to students' engagement and collaboration. The evidence from this study supports that digital and physical elements can be well blended for the support of the HCI, PBL classroom.

Acknowledgement. This project is funded by the Cyprus Research Promotion Foundation (DESMI 2009-2010) and the Slovenian Research Agency (ARRS), under the "Bilateral Cooperation" between Slovenia and Cyprus ( $\triangle$ IAKPATIKE $\Sigma / K Y-\Sigma \Lambda O / 0411)$.

\section{References}

1. Hung, W., Jonassen, D.H., Liu, R.: Problem-based learning. In: Spector, J.M., van Merriënboer, J.G., Merrill, M.D., Driscoll, M. (eds.) Handbook of Research on Educational Communications and Technology, 3rd edn., pp. 485-506. Erlbaum, Mahwah (2008)

2. Hmelo-Silver, C.E.: Problem-based learning: What and how do students learn? Educational Psychology Review 16, 235-266 (2004)

3. Barrows, H.S.: Problem-based learning in medicine and beyond: A brief overview. New Directions for Teaching and Learning, 3-12 (1996)

4. Schell, R., Kaufman, D.: Critical Thinking in a Collaborative Online Multimedia PBL Simulation. In: World Conference on E-Learning in Corporate, Government, Healthcare, and Higher Education, pp. 448-455. AACE, Chesapeake (2007)

5. Gürsul, F., Keser, H.: The effects of online and face to face problem based learning environments in mathematics education on students' academic achievement. Procedia - Social and Behavioral Sciences 1, 2817-2824 (2009)

6. Lo, H.-C.: Utilizing Computer-mediated Communication Tools for Problem-based Learning 12, 205-213 (2009)

7. Voos, R.: Blended learning - what is it and where might it take us? Sloan-C View 2, 2-5 (2003)

8. Woltering, V., Herrler, A., Spitzer, K., Spreckelsen, C.: Blended learning positively affects students' satisfaction and the role of the tutor in the problem-based learning process: results of a mixed-method evaluation. Advances in Health Sciences Education: Theory and Practice 14(5), 725-738 (2009) 
9. Hoic-bozic, N., Mornar, V., Boticki, I., Member, S.: A Blended Learning Approach to Course Design and Implementation 52(1), 19-30 (2009)

10. King, S., Greidanus, E., Carbonaro, M., Drummond, J., Boechler, P., Kahlke, R.: Synchronous Problem based learning e-Learning (e-PBL) in Interprofessional Health Science Education. Journal of Interactive Online Learning 9(2), 133-150 (2010)

11. Donnelly, R.: The nexus of problem-based learning and learning technology: Does it enable transformative practice? European Journal of Open, Distance and E-Learning (2009)

12. Donnelly, R.: Harmonizing technology with interaction in blended problem-based learning. Computers \& Education 54(2), 350-359 (2010)

13. Lou, S.J., Shih, R.C., Tseng, K.H., Diez, C.R., Tsai, H.Y.: How to promote knowledge transfer through a problem based learning Internet platform for vocational high school students. European Journal of Engineering 35(5), 539-551 (2010)

14. Bridges, S.M., Botelho, M.G., Tsang, P.C.S.: PBL 2.0: Blended Learning for an interactive problem-based pedagogy. Medical Education 44(11), 1131 (2010)

15. Liu, M., Toprac, P., Yuen, T.T.: What Factors Make a Multimedia Learning Environment Engaging: A Case Study. In: Zheng, R. (ed.) Cognitive Effects of Multimedia Learning, pp. 173-192. Information Science Reference, Hershey (2009)

16. Liu, M., Olmanson, J., Horton, L., Toprac, P.: Motivational Multimedia: Examining Students' Learning and Motivation as They Use a Multimedia Enriched Learning Environment (2011)

17. Walker, A., Shelton, B.E.: Problem-based educational games: Connections, prescriptions and assessment. Journal of Interactive Learning Research 19(4), 663-684 (2008)

18. Warren, S.J., Dondlinger, M.J., McLeod, J., Bigenho, C.: Opening The Door: An evaluation of the efficacy of a problem-based learning game. Computers \& Education 58(1), 397-412 (2012)

19. Parson, V., Bignell, S.: Using Problem-Based Learning Within 3D virtual worlds. Cuttingedge Technologies in Higher Education 4, 241-261 (2011)

20. Warburton, S.: Second Life in higher education: Assessing the potential for and the barriers to deploy virtual worlds in learning and teaching. British Journal of Educational Technology 40(3), 414-426 (2009)

21. Omale, N., Hung, W.C., Luetkehans, L., Cooke-Plagwitz, J.: Learning in 3-D multiuser vir-tual environments: Exploring the use of unique 3-D attributes for online problem-based learning. British Journal of Educational Technology (2009)

22. CHI student Design Competition, http: //chi2013 . acm.org/authors/call-forparticipation/student-competitions/student-design-competition/ 